\title{
Comparison of central corneal thickness estimated by an ultrasonic pachymeter and non-contact specular microscopy
}

\author{
Comparação da espessura central de cómea estimada por um paquímetro ultrassônico \\ e por um microscópio especular sem contato
}

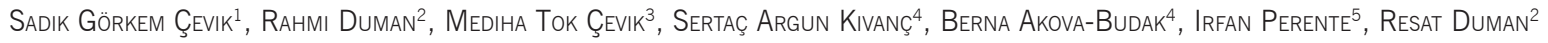

\begin{abstract}
Purpose: To compare central corneal thickness (CCT) measurements of healthy individuals obtained with ultrasonic pachymetry (UP) and non-contact specular microscopy (NCSM).

Method: In total, 148 eyes of 74 subjects with no ocular or systemic diseases were included in the study. Central corneal thickness measurements of all patients performed with UP and NCCM were compared.

Results: A total of 74 subjects (38 females) were included in this study. The mean age was $45.2 \pm 18.4$ (range 12-85) years. The mean central corneal thickness of all 148 eyes was $546.9 \pm 40 \mu \mathrm{m}$ with UP and $510.8 \pm 42 \mu \mathrm{m}$ with NCSM. The mean central corneal thickness measured with NCSM was $35 \mu \mathrm{m}$ thinner than that measured with UP $(p<0.001)$. A high degree of agreement was found between the two methods $(r=0.942, p<0.001)$.

Conclusions: Our results suggest that NCSM measures thinner corneas than UP and that the correction formula we identified should be applied when comparing
\end{abstract} between these two devices.

Keywords:Cornea/pathology; Corneal pachymetry;Microscopy/methods; Cornea/ anatomy \& histology; Comparative study

\section{RESUMO}

Objetivo: Comparar as medidas de espessura central corneana (CCT) de indivíduos saudáveis obtidos pela paquimetria ultrassônica (UP) e microscopia especular sem contato (NCSM).

Método: Cento e quarenta e oito olhos de 74 indivíduos que não tinham doenças oculares ou sistêmicas foram incluídos no estudo. Medidas da espessura central corneana de todos os pacientes foram comparadas entre UP (SP 100, Tomey, Nagoya, Japão) e do NCSM (NSP-9900, Konan Medical, Inc., Hyogo, Japão).

Resultados: Um total de 74 indivíduos (38 mulheres) foram incluídos neste estudo. A idade média foi de 45,2 \pm 18,4 (variação 12-85) anos. A medida média da espessura central corneana de todos os 148 olhos foi 546,9 $\pm 40 \mu \mathrm{m}$ com UP e 510,8 $\pm 42 \mu \mathrm{m}$ com NCSM. A espessura central corneana média avaliada pelo NCSM foi de $35 \mu \mathrm{m}$ mais fina do que a UP $(p<0,001)$. Foi encontrado um elevado grau de concordância entre os dois métodos $(r=0,942, p<0,001)$.

Conclusões: Nossos resultados sugerem que a microscopia especular sem contato mede córneas mais finas em comparação com a UP e que o fator de correção identificado deve ser aplicado ao fazer comparações entre esses dois aparelhos.

Descritores: Córnea/patologia; Paquimetria corneana; Microscopia/métodos; Córnea/anatomia \& histologia; Estudo comparativo

\section{INTRODUCTION}

The measurement of central corneal thickness plays an important role in the prognosis and treatment of many corneal diseases and glaucoma. It is also critical for refractive surgery management ${ }^{(1,2)}$. Central corneal thickness (CCT) can be measured using an ultrasonic pachymeter (UP) or with specular microscopy, corneal topography screening, confocal microscopy, optical coherence tomography, and the Scheimpflug imaging method ${ }^{(3)}$. Many modern contact and non-contact pachymetry measurement methods have been described; however, UP is still considered the gold standard(4).

In this study, we aimed to compare CCT of healthy individuals measured by UP and non-contact specular microscopy (NCSM) and to determine the average difference between the two measurements.

\section{METHODS}

We evaluated 148 eyes from 74 healthy subjects who consented to participation in this study. The study was conducted in the Şevket YılmazTraining and Research Hospital between March, 2015 and June,
2015. Full ophthalmological examination was performed before measuring pachymetry. The patients with ocular diseases (corneal scar, cataract, glaucoma and keratoconus, or retinal disease), history of contact lens wear, dry eye, any systemic diseases, or a history of previous ocular surgery were excluded from the study. Patients with best-corrected visual acuity of 20/20 were included.

In order to avoid the potential effect of epithelial compression on consecutive measurements at the same location, CCT measurements were first taken via non-contact specular microscope NSP-9900 (Konan Medical, Inc., Hyogo, Japan). At the second stage of the study, CCT measurement was performed using an ultrasound pachymeter SP-100 (Tomey, Nagoya, Japan), which operates at $20 \mathrm{MHz}$, for measuring thicknesses in the range of 150 to $1200 \mu \mathrm{m}$ with calibration at speeds ranging from 1400 to $2000 \mathrm{~m} / \mathrm{s}^{(5)}$. Topical anesthetic drops (0.5\% proparacaine hydrochloride Alcaine ${ }^{\circledR}$, Alcon) were instilled in all patients 1.5 to 2 minutes $^{(6)}$ before UP measurements.

NCSM and UP measurements were taken three times in the center of the cornea. For both measurements, average values were taken to compare pachymetry values.

Submitted for publication: August 4, 2015

Department of Ophthalmology, Şevket Yılmaz Education and Training Hospital, Bursa, Turkey.

2 Department of Ophthalmology, Kocatepe University, Afyon, Turkey.

3 Department of Ophthalmology, Düziçi State Hospital, Osmaniye, Turkey.

${ }^{4}$ Department of Ophthalmology, Uludag University, Bursa, Turkey.

5 Department of Ophthalmology, Beyoglu Goz Education and Training Hospital, Istanbul, Turkey.

Funding: No specific financial support was available for this study.

Disclosure of potential conflicts of interest: None of the authors have any potential conflict of interest to disclose.

Corresponding author: Sadık Görkem Çevik. Şevket Yılmaz Education and Training Hospital. Bursa 16310 - Turkey - E-mail: gorkemcevik@hotmail.com

Approved by the following research ethics committee: Şevket YIImaz Training and Research HoSpital (\#2015/13-05). 
All measurements were taken by one of the two authors (SGÇ or RD) in the afternoon, between 14:00 and 16:00 during a single visit. The study was planned and conducted in accordance with the Helsinki Declaration. A patient consent form was obtained from all participants.

\section{Statistical analysis}

Descriptive statistics included mean, standard deviation, minimum values, and maximum values. The distribution of the variables was measured with the Kolmogorov Simirnov test. In the analysis of the repeated measurements, a Wilcoxon test was used. A chi square test was utilized in the analysis of qualitative data. When chi square test conditions were not met a Fischer test was applied. Intra-class analysis was undertaken for correlation. The changes across measurements were assessed using Bland-Altman graphics. For the analyses, the SPSS 22.0 program was used.

\section{RESULTS}

One hundred and forty-eight eyes from 74 patients (36 (49\%) males, 38 (51\%) females) were assessed in this study. The mean age of participants was $45.2 \pm 18.4$ (12-85) years. The mean CCT measurement of all 148 eyes was $546.9 \pm 40 \mu \mathrm{m}$ with UP and $510.8 \pm 42 \mu \mathrm{m}$ with NCSM. Ultrasonic pachymetry and NCSM measurement results were around the equality line shown in figure 1. The mean CCT was $35 \mu \mathrm{m}$ thicker in the UP group and the difference between groups was statistically significant $(p<0.001)$.

Among the 148 eyes, corneal thickness measured with NCSM and UP devices showed significant and strong correlation ( $r=0.942 /$ $\mathrm{p}<0.001$ ). In all 148 eyes, the NCSM device measured corneal thickness as significantly $(p<0.001)$ more thin than the UP device.

The equation, $y=32.2+0.99 \times\left(R^{2}=0.887\right)$, was attained via a regression model according to the CCT measurements with NCSM $(x)$ and UP (y). The assumption that the values taken with the NCSM device will be 32 units lower than the UP per measurement has been proven to be a strong premise. Figure 2 presents the Bland-Altman plot demonstrating good agreement between the UP and NCSM methods for measurement of CCT.

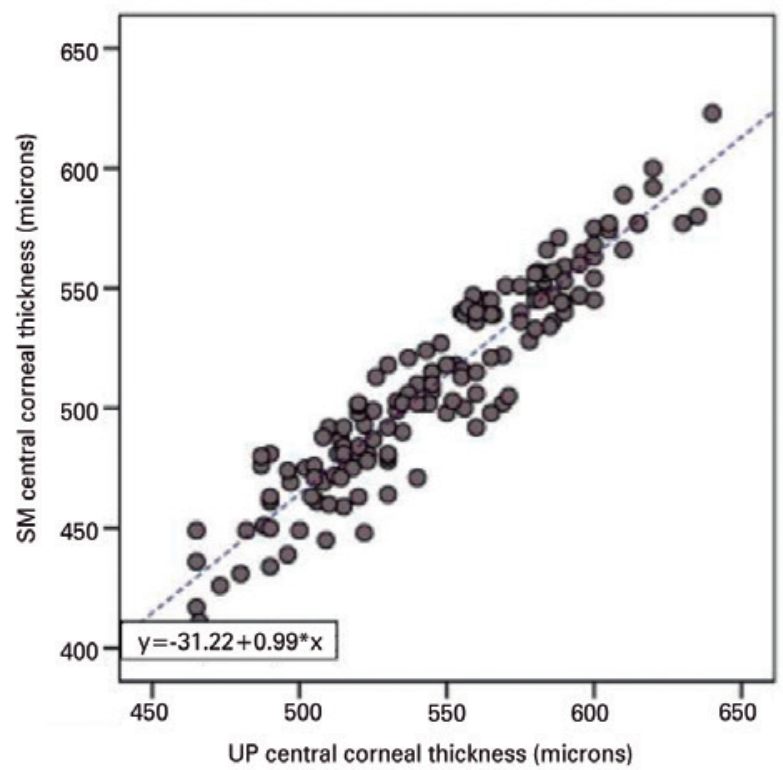

Figure 1. Scatter plots between central corneal thickness measurements (microns) acquired with non-contact specular microscope NCSM and ultrasound pachymetry (UP) showing a linear regression of $y=31.22+0.99 x$.

\section{DISCUSSION}

CCT is a parameter that has a very wide range of applications for diagnosis and treatment of ocular diseases. In particular, when considering the clinical impact of the smallest changes in refractive surgery and glaucoma follow-up, the importance of measuring CCT in the most reliable way cannot be understated ${ }^{(1,4,7)}$.

Although UP is the gold standard method, several non-contact measurement methods are sometimes preferred to ensure accurate measurement, need for contact with the cornea, and the capability to make measurements on multiple areas simultaneously ${ }^{(8,9)}$. On the other hand, UP is currently the cheapest and most widely used method for CCT measurement. In this study, we compared UP, which only measures corneal thickness, and NCSM, which has the capacity to evaluate the endothelium and measure CCT at the same time.

There are many studies in the literature comparing CCT measurements methods and devices for normal corneas. Most of these studies reported that UP measurements were thicker than NCSM measurements ${ }^{(10-13)}$. Modis et al. examined 73 eyes from 44 patients (mean age 66 years) with normal corneas comparing three different devices: NCSM (Topcon SP-2000P; Topcon Corporation, Tokyo, Japan), UP (AL-1000; Tomey, Erlangen, Germany), and contact specular microscope (CSM) (EM-1000; Tomey, Tokyo, Japan). The normal mean CCT was measured as $542 \pm 46 \mu \mathrm{m}$ with NCSM, $570 \pm 42 \mu \mathrm{m}$ with UP, and $638 \pm 43 \mu \mathrm{m}$ with CSM. The NCSM measurement was found to be significantly lower than the UP measurement ${ }^{(10)}$. Al-Ageel and Al Muammar reported that CCT was significantly thinner when measured with specular microscope (SM) (511.9 \pm 38.6$)($ SP-2000P, Topcon Corporation, Tokyo, Japan) than when measured with UP (533.3 \pm 37.9) (SP-3000, Tomey Corporation, Nagoya, Japan) and that the two instruments were in good correlation while measuring 94 normal eyes of 47 patients, with a mean age of 33 years ${ }^{(12)}$. In a multicenter study in Japan, both Orbscan and UP measurements were significantly higher than NSCM (SP-2000P, Topcon Corporation, Tokyo, Japan) measurements and ultrasonic pachymetry correlated with NCSM ${ }^{(13)}$. In contrast, Khaja et al. reported lower values when comparing measurements made by UP vs. SM. The authors compared CCT measurements of 4 different devices in 32 healthy eyes of 32 subjects (mean age: 31 years). The authors compared, UP, slit-lamp optical coherence

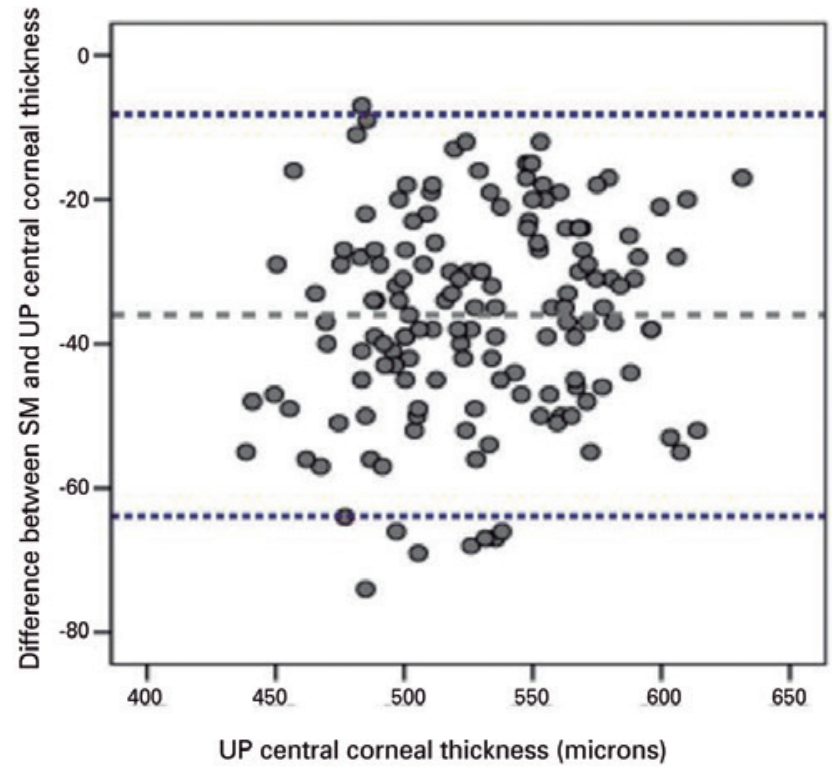

Figure 2. Bland-Altman plot showing the correlation between central corneal thickness (microns) acquired with non-contact specular microscope NCSM and ultrasound pachymetry (UP). 
tomography (OCT), SM (Konan Medical Corporation, Fairlawn, NJ, USA), and Orbscan, and found that the mean CCT was $557 \pm 49.92 \mu \mathrm{m}$ on SM and $548 \pm 48.68 \mu \mathrm{m}$ on UP. However, they did not find this difference significant. This was in contrast with our findings, although it is possible that our studies limited sample size may have influenced our findings. It has also been reported that UP correlates with SM ${ }^{(14)}$. Wu et al. measured the CCT of 322 eyes in 173 normal subjects using the Konan non-contact specular microscope to determine whether this method was reliable or not and was able to confirm this method's efficacy ${ }^{(15)}$. Differences in measurement between UP and NCSM devices may be caused by the different working systems of each device. In cases of ultrasound pachymetry, the exact posterior corneal reflection point is not known; it may be located between the Descemet membrane and the anterior chamber ${ }^{(16)}$. One other factor potentially influencing CCT measurement is tear film. Some authors have claimed that tear film thickness might be added into corneal thickness when non-contact optical devices measure CCT; however, tear film is compressed by the pachymeter probe when using UP(17-19). Reproducibility of the applications is also important, and some studies have shown that the reproducibility of the optical devices is high ${ }^{(20,21)}$. However, with UP, it is difficult to maintain the same points and the perpendicularity of the ultrasound probe in sequential measurements.

Measuring corneal thickness remains a challenge for several devices and methods. In one study, De Bernado et al. using Topcon SP3000 specular microscopy, recorded thinner measurements than an Oculus Pentacam ${ }^{(22)}$. In another study, the Pentacam and SP2000P Topcon NCSM were compared and the measurements obtained with the SP2000P were significantly smaller than those obtained with the Pentacam ${ }^{(19)}$. Fujioka et al. compared the Pentacam with NCSM (Noncon Robo; Konan medical, Japan). Measurements taken with NCSM (552.04 $\pm 42.95 \mu \mathrm{m})$ were significantly smaller than those obtained with the Pentacam $(559.49 \pm 38.44 \mu \mathrm{m})^{(23)}$. Other studies have measured CCT with the Konan NCSM; however, to the best of our knowledge this study examines the greatest number of healthy eyes while comparing CCT measurements for UP and NCSM.

In this study, one of the aims was to provide a regression formula to translate one measurement into another. We detected a strong and meaningful correlation between NCSM and the gold standard, UP. We found a difference of 32 units between measurements of the two devices, which may exist on the grounds of the change in possible reference points. We also think that a regression model can be used to convert the measurements of both devices and thus established the equation $y=32.2+0.99 x$. This conversion may help assess patients who are referred to a clinic that uses a different measurement device (e.g., UP is used and NCSM measurements from other clinic have to be converted). However, this does not mean that these measurement methods are interchangeable. Bourges et al. reported that non-contact methods are reproducible and interchangeable with each other; however, interchangeability with UP has been found to be limited(21).

In conclusion, in this study we obtained thinner CCT measurements with NCSM compared to UP, widely regarded to be the gold standard. We think the differences between the devices is due to the different reference points these devices use for the measurements. In addition, the impact of the drops used for anesthesia and the reference points taken from the posterior cornea for the measurements could not be precisely explained.

These results confirm that SM measures significantly thinner corneas compared to UP. This could be due to the fact that the two machines measure different corneal points. This means that it is hard to estimate which of the two systems generates more accurate results in finding the closest value to the real value of CCT. The regression formulas given in this study could help more easily translate one measurement into another and this helps us to compare and evaluate CCT and intraocular pressure (IOP) from the former CCT and IOP history. As mentioned by Bourges et al.(21), we also believe that reproducibility and interchangeability in methods without contact to the cornea, in relation to ultrasound pachymetry, may allow for the non-contact devices to become gold standards for measuring CCT.

\section{REFERENCES}

1. Doughty MJ, Zaman ML. Human corneal thickness and its impact on intraocular pressure measures: A review and meta-analysis approach. Surv Ophthalmol. 2000;44(5): 367-408

2. Ge L, Yuan Y, Shen M, Tao A, Wang J, Lu F. The role of axial resolution of optical coherence tomography on the measurement of corneal and epithelial thicknesses. Invest Ophthalmol Vis Sci. 2013 28:54(1):746-55.

3. Çakıcı Ö. Santral corneal kalınlığının klinik önemi ve santral kornea kalınlığı ölçüm yöntemlerinin karşılaştırılması. J Clin Exp Invest. 2014:5(1):153-8.

4. Lackner B, Schmidinger G, Pieh S, Funovics MA, Skorpik C. Repeatability and reproducibility of central corneal thick- ness measurement with Pentacam, Orbscan, and ultrasound. Optom Vis Sci. 2005;82(10):892-9.

5. Queirós A, González-Méijome JM, Fernandes P, Jorge J, Almeida JB, Parafita MA. Accuracy and repeatability of a new portable ultrasound pachymeter. Ophthalmic Physiol Opt. 2007;27(2):190-3

6. Nam SM, Lee HK, Kim EK, Seo KY. Comparison of corneal thickness after theinstillation of topical anesthetics: proparacaine versus oxybuprocaine. Cornea. 2006;25(1):51-4.

7. Shetgar AC, Mulimani MB. The central corneal thickness in normal tension glaucoma, primary open angle glaucoma and ocular hypertension. J Clin Diagn Res. 2013;7(6): 1063-7.

8. Marsich MW, llimore MA. The repeatability of corneal thickness measures. Cornea. 2000; 19(6):792-5.

9. Miglior S, Albe E, Guareschi M, Mandelli G, Gomarasca S, Orzalesi N. Intraobserver and interobserver reproducibility in the evaluation of ultrasonic pachymetry measurements of central corneal thickness. Br J Ophthalmol. 2004 88(2):174-7.

10. Módis L Jr, Langenbucher A, Seitz B. Corneal thickness measurements with contact and noncontact specular microscopic and ultrasonic pachymetry. Am J Ophthalmol. 2001:132(4):517-21.

11. Bovelle R, Kaufmann SC, Thompson HW, Hamano H. Corneal thickness measurements with the Topcon SP-2000P specular microscope and an ultrasound pachymeter. Arch Ophthalmol. 1999;117(7):868-70.

12. Al-Ageel S, Al-Muammar AM. Comparison of central corneal thickness measurements by Pentacam, noncontact specular microscope, and ultrasound pachymetry in normal and post-LASIK eyes. Saudi J Ophthalmol. 2009;23(3-4):181-7.

13. Suzuki S, Oshika T, Oki K, Sakabe I, Iwase A, Amano S, et al. Corneal thickness measurements: scanning-slit corneal topography and noncontact specular microscopy versus ultrasonic pachymetry. J Cataract Refract Surg. 2003;29(7):1313-8.

14. Khaja WA, Grover S, Kelmenson AT, Ferguson LR, Sambhav K, Chalam KV. Comparison of central corneal thickness: ultrasound pachymetry versus slit-lamp optical coherence tomography, specular microscopy, and Orbscan. Clin Ophthalmol. 2015;9:1065-70.

15. Wu Q, Duan X, Jiang Y, Qing G, Jiang B, Shi J. [Normal value of the central cornea thickness measured by non-contact specular microscope]. Yan Ke Xue Bao. 2004; 20(4):229-32. Chinese

16. Nissen J, Hjortdal JO, Ehlers N, Frost-Larsen K, Sørensen T. A clinical comparison of optical and ultrasonic pachometry. Acta Ophthalmol Scan. 1991;69(5):659-63.

17. Kim HY, Budenz DL, Lee PS, Feuer WJ, Barton K. Comparison of central corneal thickness using anterior segment optical coherence tomography vs ultrasound pachymetry. Am J Ophthalmol. 2008;145(2):228-32

18. Bayhan HA, AslanBayhan S, Can I. Comparison of central corneal thickness measurements with three new optical devices and a standard ultrasonic pachymeter. Int J Ophthalmol. 2014;7(2):302-8.

19. Uçakhan OO, Ozkan M, Kanpolat A. Corneal thickness measurements in normal and keratoconic eyes: Pentacam comprehensive eye scanner versus noncontact specular microscopy and ultrasound pachymetry. J Cataract Refract Surg. 2006;32(6):970-7.

20. Muscat S, McKay N, Parks S, Kemp E, Keating D. Repeatability andreproducibility of corneal thickness measurements by optical coherence tomography. Invest Ophthalmol Vis Sci. 2002;43(6):1791-5.

21. Bourges JL, Alfonsi N, Laliberté JF, Chagnon M, Renard G, Legeais JM, et al. Average 3-dimensional models for the comparison of Orbscan II and Pentacam pachymetry maps in normal corneas. Ophthalmology. 2009;116(11):2064-71.

22. De Bernardo M, Borrelli M, Mariniello M, Lanza M, Rosa N. Pentacamvs SP3000P specular microscopy in measuring corneal thickness. Cont Lens Anterior Eye. 2015; 38(1):21-7.

23. Fujioka M, Nakamura M, Tatsumi Y, Kusuhara A, Maeda H, Negi A. Comparison of Pentacam Scheimpflug camera with ultrasound pachymetry and noncontact specular microscopy in measuring central corneal thickness. Curr Eye Res. 2007:32(2):89-94. 